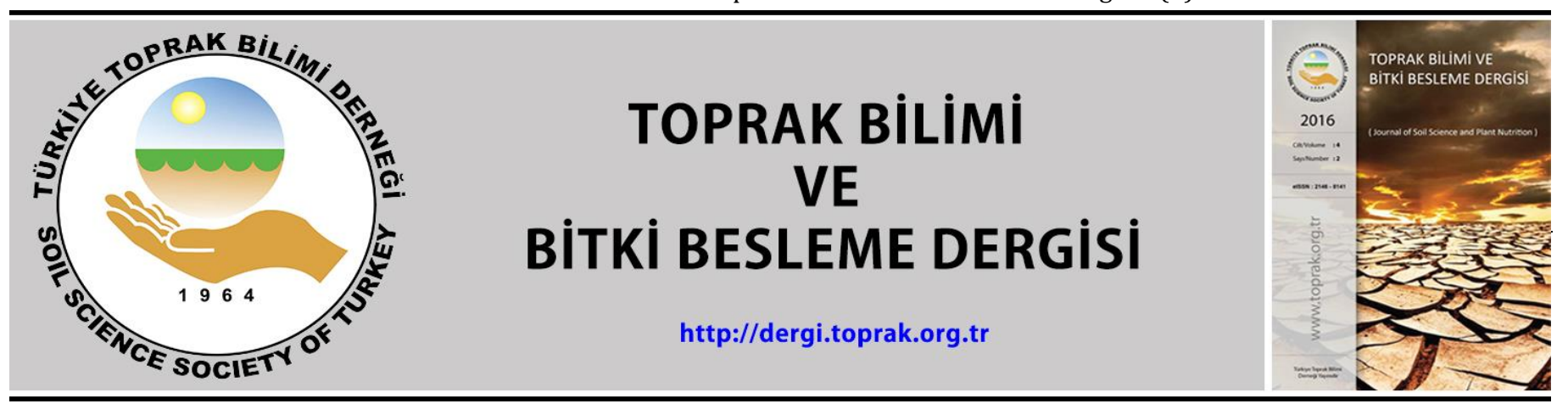

\title{
Tek yıllık yem bitkisi yetiştiriciliği altındaki su tutucu uygulanmış topraktan meydana gelen sediment ve yüzey akış
}

\section{Tuğrul Yakupoğlu1,*, Erdem Gülümser², Medine Çopur Doğrusöz ${ }^{3}$, Uğur Başaran³}

\author{
${ }^{1}$ Yozgat Bozok Üniversitesi, Ziraat Fakültesi, Toprak Bilimi ve Bitki Besleme Bölümü, Yozgat \\ ${ }^{2}$ Bilecik Şeyh Edebali Üniversitesi, Ziraat ve Doğa Bilimleri Fakültesi, Tarla Bitkileri Bölümü, Bilecik \\ ${ }^{3}$ Yozgat Bozok Üniversitesi, Ziraat Fakültesi, Tarla Bitkileri Bölümü, Yozgat
}

\begin{abstract}
Özet
Küresel ısınmanın beraberinde getirdiği iklim değişikliği bütün ekosistemleri olduğu gibi tarımsal ekosistemi de olumsuz yönde etkilemektedir. Bu olumsuz etkilerin bașta sayılabileceklerinden biri tarımda su yetersizliğidir. Bu çalıșmanın amacı, mısır (Zea mays L.) ve soya (Glycine max L.) yetiştiriciliği yapılan bir yarı-kurak iklim bölgesi tarım toprağından meydana gelen yüzeysel akışlar ve toprak kaybı üzerine, Natural Aquatic® isimli samanlı su tutucunun farklı dozlarının etkilerinin laboratuar koşullarında, yapay yağıș altında belirlenmesidir. Bu amaçla, erozyon tavalarına yerleștirilmiş kil bünyeli bir toprağa farklı dozlarda samanlı su tutucu uygulanmıştır. Bitki yetiştiriciliği periyodunda ve sonrasındaki bir hafta boyunca tavalar kontrollü şartlarda tutulmuştur. Bitkiler tavalardan uzaklaştırıldıktan bir hafta sonra tavaların üzerine $360 \mathrm{~mm} \mathrm{~h}^{-1}$ yoğunlukta yapay yağış 4 dakika süre ile yağdırılmıştır. Değişken olarak yüzeysel akışın başlama zamanı, kalınlığı ve bu akışla meydana gelen toprak kaybı ölçülmüştür. Elde edilen sonuçlara göre, yüzeysel akışın başlaması için geçen süre ile oluşan akışın kalınlığı birbiri ile ilişkilidir. Taşınan toprak miktarına kullanılan su tutucu dozunun etkisi istatistiksel bakımdan önemlidir $(P<0.05)$. Bitkisiz ve mısır yetiştirilen gruplar için toprak ve su kayıplarını azaltmada \%0.2 ve \%0.4 uygulamaları en etkili dozlar iken soya yetiştirilen grupta en etkili uygulama \%1 dozudur.
\end{abstract}

Anahtar Kelimeler: Erozyon, mısır, soya, su tutucu polimer, toprak, yapay yağış.

\section{Sediment and runoff from the soil amended superabsorbent polymer under annual forage crop} grown

\begin{abstract}
Climate change brought about by global warming adversely affects all ecosystems as well as agricultural ecosystems. One of these negative effects is the of water deficiency in agriculture. The objective of this study was to investigate the effects of different doses of a superabsorbent mixed straw called Natural Aquatic ${ }^{\circledR}$ on runoff and soil loss from a semi-arid climate zone agricultural soil cultivated with corn (Zea mays L.) and soybean (Glycine max L.) under rainfall simulation. For this purpose, different doses of superabsorbent polymer were applied to a clay soil placed in erosion pans. The pans were kept under controlled conditions during the plant breeding period and a week after this period. One week after the plants were removed from the pans, artificial rainfall with $360 \mathrm{~mm} \mathrm{~h}^{-1}$ intensity was poured on the pans for a duration 4 minutes. As variables, runoff starting time, runoff quantity, and the soil loss generated by this flow were measured. According to the results obtained, runoff starting time and runoff quantity was related to each other. The effect of the superabsorbent application dose on soil amount transported from pans was statistically significant $(P<0.05)$. For non-plant and corn-cultivated groups, $0.2 \%$ and $0.4 \%$ were the most effective doses in reducing soil and water losses, while the most effective application was a $1 \%$ dose in soybean grown group.

Keywords: Erosion, maize, soybean, rainfall simulation, soil, superabsorbent polymer.
\end{abstract}

(C) 2019 Türkiye Toprak Bilimi Derneği. Her Hakkı Saklıdır

\section{Giriş}

Küresel ısınmanın beraberinde getirdiği iklim değişikliği bütün ekosistemleri olduğu gibi tarımsal ekosistemi de olumsuz yönde etkilemektedir. Bu olumsuz etkilerin başta sayılabileceklerinden biri kuraklıktır. Bitki yetiştirme periyodu boyunca etkili kök derinliğinde yeterli su bulunmaması ürünün niceliğini ve niteliğini olumsuz yönde etkilemektedir. Özellikle kil miktarının düşük ve organik maddenin az olduğu kurak ve yarı kurak bölgelerin çoğu toprakları düşük su tutma kapasitesi ile karakterize edilirler (Yu

\footnotetext{
* Sorumlu yazar:

Tel. : $\quad 03542421028$

E-posta

Geliş Tarihi

Kabul Tarihi
}

01 Ekim 2018

25 Ekim 2019
e-ISSN

DOI : $10.33409 /$ tbbbd.668644 
ve ark., 2012). Yüzey toprağının su tutma kapasitesi düşük olduğunda toprağa gelen su (yağış, sulama) kök bölgesinin altına aşırı drene olmaktadır (Fan ve ark., 2005).

Özellikle kurak ve yarı kurak bölgelerde yapılan tarım için toprağın su tutma kapasitesini artırmaya yönelik birçok uygulama geliştirilmiştir. Bu uygulamalardan bir tanesi de superabsorbent polimer olarak bilinen su tutucuların kullanımıdır. Yüksek su tutma kapasiteleri nedeniyle "su tutucu" olarak isimlendirilen hidrojeller, tarımsal üretimi için temel sorunlardan birinin su kıtlığı olduğu kurak ve yarı kurak bölgelerin topraklarında bitkinin büyüme ve gelişimini desteklerler (Johnson ve Piper, 1997; Lobo ve ark., 2006). Genel olarak çapraz bağlı bir polimer zincirinden oluşan bu superabsorbent polimerler, geleneksel absorbent materyallerin tuttuğundan çok daha fazla suyu bünyelerinde tutabilirler (Esposito ve ark., 1996; Raju ve ark., 2003). Bu su tutucular kendi ağırlıklarının beş yüz katına kadar su tutabilmekte olup (Kazanskii ve Dubrovskii, 1992) toprağa uygulandığında toprakların su tutma kapasitesini iki katına kadar artırabilirler (Bhardwaj ve ark., 2007; Karimi ve ark., 2009).

Yürütülen birçok çalışmada; su tutucu polimerlerin kullanımı ile bitkinin su stresinin azalabildiği, toprağın su tutma kapasitesinin arttığı, ardışık sulamalar arasındaki zamanın uzayabildiği, bitki gelişim oranı ve performansı ile kök ağırlığının arttı̆̆ı gibi birçok yararlar sağlandığı belirtilmiştir (Pill ve Jacono, 1984; Baker, 1990; Hutterman ve ark., 1999; Viero ve ark., 2002; Han ve ark., 2005; Ekebafe, 2011; Yu ve ark., 2012).

Nnadi ve Brave (2011) su tutucu polimer kullanarak yürüttükleri bir çalışmada, yetiştirildiği toprağa su tutucu ilave edilmeyen bitkilerin su stresi periyodu boyunca dehidrasyon belirtileri gösterdiğini, su tutucu uygulanan toprakta yetiștirilen bitkilerin ise daha sağlıklı olduklarını gözlemlemişlerdir. Araştırmacılar ayrıca biyopolimer olarak isimlendirilen biyolojik kökenli polimerlerin petrol türevi olan polimerlerin yerini alabileceğini ve bunun çevre açısından daha güvenli olduğunu açıklamışlardır.

Su tutucunun konu edildiği başka bir çalışmada (Bhardwaj ve ark., 2007) kumlu bir toprağın hidrolik iletkenliği ve su tutması üzerine hem sudaki elektrolit konsantrasyonu hem de superabsorbent polimerin özellikleri etki etmiştir. Bahsi geçen çalışmada araştırmacılar, su tutucu karıştırılmış kumlu toprağa musluk suyu verildiğinde toprak-hydrogel karışımında serbest boşluk hacmi azaldığı için başlangıçta hidrolik iletkenliğin düştüğünü, sonrasında ise şişen superabsorbent granüllerinden suyun drene olması sonucu su hareketi için yarayışlı por büyüklüğündeki artışla hidrolik iletkenliğin artarak sabit bir değere ulaştığını belirlemişlerdir.

Tarımdaki fazlaca olumlu katkısının yanı sıra su tutucu materyallerin henüz açıklanamamış birçok yönü bulunmaktadır. Kullanımının yüksek maliyetli olması, toprak fiziksel özellikleri, su yarayışlılığı ve verim üzerine olumlu etkilerinin her yönüyle açıklığa kavuşturulamamış olması ve topraktaki etki sürelerinin değişken olması, bu materyallerin en büyük açmazlarıdır. Öte yandan superabsorbent polimerlerin su sağlamada bitkiye faydalı olmadığı yönünde hatta bitki yaşamına ve ürüne zarar verdiği yönünde bazı sonuçların elde edildiği bildirilmektedir (Ingram ve Yeager, 1987; Busscher ve ark., 2009; Han ve ark., 2010; Yu ve ark., 2012).

Yukarıda sıralanan olumsuzlukların, henüz superabsorbent materyalin farklı şartlarda ve değisşik dozlarda denenmemiş olmasından kaynaklandığını düşünülmektedir. Çalışmalarda farklı bitki, polimer dozu, polimer çeşidi, iklim koşulları, sulama rejimi kombinasyonlarının henüz yeterince denenmemiş olmasının, bu polimerlerin kullanımı konusunda çiftçilerin cesaretini kırdığı, bu nedenle de maliyetlerin düşmediği kanaati oluşmuştur. Denemelerin sınırlı olması birtakım çalışma sonuçlarının tutarlı bir şekilde açılanmasının önüne geçmektedir. Öte yandan, erozyon çalışmalarında kullanılan PAM, PVA gibi polimerler bir yana, kendi ağırlıklarının on katına kadar su tutup anında şişen su tutucu polimerlerin (superabsorbent polimerlerin) eğimli arazilerde toprak ve su kayıpları üzerine etkileri ile ilgili çalışma yok denecek kadar azdır. Sıralanan düşünceler ve gerçeklerden hareketle, bu çalışmanın amacı, mısır (Zea mays L.) ve soya (Glycine max L.) yetiştiriciliği yapılan bir yarı-kurak iklim bölgesi tarım toprağından meydana gelen yüzeysel akışlar ve taşınan sediment miktarı üzerine, Natural Aquatic® isimli samanlı su tutucunun farklı dozlarının etkilerinin laboratuar koşullarında, yapay yağış altında belirlenmesidir.

\section{Materyal ve Yöntem}

\section{Denemede kullanılan topraklar}

Bu çalışmada kullanılan topraklar, Yozgat Bozok Üniversitesi Tarımsal Araştırma ve Uygulama Merkezi (TUAM) denetiminde bulunan Yozgat ili Merkez ilçesi Topçu mevkiinde yer alan deneme arazilerinden alınmıştır. Söz konusu arazinin koordinatları $39^{\circ} 45^{\prime} 08^{\prime \prime} \mathrm{N}$ ve $34^{\circ} 48^{\prime} 13^{\prime \prime} \mathrm{E}$ olup deniz seviyesinden yüksekliği 1265 m’dir. Toprakların alındığı yörenin uzun yıllar (1929-2017) iklim verilerine göre yıllık ortalama 
sıcaklığı $9^{\circ} \mathrm{C}$ iken yıllık yağış ortalaması $560.9 \mathrm{~mm}$ olup (MGM, 2018) bölge yarı-kurak iklim bölgesidir. Arazide işlemeli tarım yapılmaktadır. Toprak almada bozulmuş toprak örneği alma esasları izlenmiş ve topraklar 0-30 cm derinlikten alınmıștır. Denemede kullanılan toprakların bazı özellikleri Çizelge 1'de sunulmuştur. Deneme toprağı kil bünyeli, reaksiyon bakımından nötr, hafif tuzlu, orta kireçli, organik madde seviyesi orta, Na zararı bulunmayan bir topraktır (Yakupoğlu, 2018).

Çizelge 1. Natural Aquatic® su tutucunun bazı özellikleri (Anonim 2018a,b)

\begin{tabular}{llll}
\hline Özellik & Ölçüm değeri & Özellik & Ölçüm değeri \\
\hline pH & 6.7 & $\mathrm{Cu}\left(\mu \mathrm{g} \mathrm{g}^{-1}\right)$ & 9.55 \\
Organik madde (\%) & 59.1 & $\mathrm{~Pb}\left(\mu \mathrm{g} \mathrm{g}^{-1}\right)$ & 2.49 \\
Nem (\%) & 6.7 & $\mathrm{Zn}\left(\mu \mathrm{g} \mathrm{g}^{-1}\right)$ & 26.8 \\
Suda Çözünebilir K ${ }_{2} \mathrm{O}(\%)$ & 5.7 & $\mathrm{Hg}\left(\mu \mathrm{g} \mathrm{g}^{-1}\right)$ & 0.028 \\
Su tutma kapasitesi & $222 \mathrm{~kat}$ & $\mathrm{Cr}\left(\mu \mathrm{g} \mathrm{g}^{-1}\right)$ & $<0.01$ \\
$\mathrm{Cd}\left(\mu \mathrm{g} \mathrm{g}^{-1}\right)$ & 0.71 & $\mathrm{Ni}\left(\mu \mathrm{g} \mathrm{g}^{-1}\right)$ & 2.07 \\
\hline
\end{tabular}

\section{Denemeye konu olan su tutucu polimer}

Çalışmada kullanılan polimer çapraz bağlı, akrilik asit potasyum akrilat kopolimeridir. Bu polimerin bileşimine belirli oranda saman ilave edilmiş ve Natural Aquatic® isimli su tutucu elde edilmiştir. Bu superabsorbent bileşimindeki saman sayesinde daha doğal bir yapıya sahiptir. Samanın bileşimi ortalama değerlere göre \% 65-75 selüloz, \% 15-20 hemiselüloz ve pentozanlar, \%5-10 lignin, \% 1-3 mum ve protein, \% 2-10 silis gibi mineraller ve az miktarda nişastadan oluşmaktadır. Samanla geliștirilen bu su tutucunun içerisinde farklı oranlarda $\mathrm{C}, \mathrm{H}, \mathrm{O}$ ve $\mathrm{K}$ ile saman ve samandan gelebilecek elementler bulunmaktadır. Natural Aquatic ${ }^{\circledR}$ polimerin samanla modifiye edilmesinin amacı su tutma kapasitesi çok daha yükseltebilmek ve kısmen organik materyallerden oluşan bir su tutucu geliştirmek istenmesidir. Natural Aquatic ${ }^{\circledR}$ su ve besin tutabilen kullanımı kolay bir toprak katkı maddesidir. Bu ürün, yağmur ve sulama sularını bünyesine alarak hacminin 200-300 katı suyu bitki kök bölgesinde muhafaza eder. Natural Aquatic® ayrıca bitki kök bölgesinde sürekli hazır bir su deposu görevi üstlenerek bitkinin ihtiyacı olan suyu bitkinin tüketimine sunar. Ürünün bazı özellikleri Çizelge 2'de verilmiştir (Anonim 2018a,b).

Çizelge 2. Deneme toprağının bazı özellikleri (Yakupoğlu, 2018)

\begin{tabular}{|c|c|c|c|c|c|c|c|c|c|}
\hline Değişken & $\begin{array}{c}\text { Kil } \\
\left(\mathrm{g} \mathrm{kg}^{-1}\right)\end{array}$ & $\begin{array}{c}{ }^{*} \text { Silt } \\
\left(\mathrm{g} \mathrm{kg}^{-1}\right)\end{array}$ & $\begin{array}{c}\text { Kum } \\
\left(\mathrm{g} \mathrm{kg}^{-1}\right)\end{array}$ & $\begin{array}{c}\text { Tekstür } \\
\text { sinıfi }\end{array}$ & ${ }^{* *} \mathrm{pH}$ & $\begin{array}{c}{ }^{* *} \text { Tuz } \\
(\%)\end{array}$ & $\begin{array}{c}\mathrm{CaCO}_{3} \\
(\%)\end{array}$ & $\begin{array}{l}\text { OM } \\
(\%)\end{array}$ & $\begin{array}{l}\text { ESP } \\
(\%)\end{array}$ \\
\hline Ölçüm değeri & 476 & 138 & 386 & $\mathrm{C}$ & 7.09 & 0.178 & 7.15 & 2.49 & $<15$ \\
\hline Değişken & $\begin{array}{c}\text { Total N } \\
(\%)\end{array}$ & $\begin{array}{c}\mathrm{P} \\
\left(\mu \mathrm{g} \mathrm{g}^{-1}\right)\end{array}$ & $\begin{array}{c}{ }^{* * *} \mathrm{~K} \\
(\mu \mathrm{g} g-1)\end{array}$ & $\begin{array}{c}{ }^{* * *} \mathrm{Ca} \\
(\mu \mathrm{g} g-1)\end{array}$ & $\begin{array}{c}{ }^{* * *} \mathrm{Mg} \\
(\mu \mathrm{g} g-1)\end{array}$ & $\begin{array}{c}{ }^{* * * *} \mathrm{Fe} \\
(\mu \mathrm{gg}-1)\end{array}$ & $\begin{array}{c}{ }^{* * * *} \mathrm{Cu} \\
(\mu \mathrm{g} g-1)\end{array}$ & $\begin{array}{c}{ }^{* * * *} \mathrm{Zn} \\
(\mu \mathrm{g} g-1)\end{array}$ & $\begin{array}{c}{ }^{* * * *} \mathrm{Mn} \\
(\mu \mathrm{g} g-1)\end{array}$ \\
\hline Ölçüm değeri & 0.15 & 78 & 728 & 7060 & 5604 & 8.08 & 2.84 & 0.62 & 4.07 \\
\hline
\end{tabular}

${ }^{*}$ Partikül büyüklük dağılımında USDA ölçütleri esas alınmıştır, ${ }^{* *} \mathrm{pH}$ ve tuzluluğu hesaplama için $\mathrm{EC}_{25^{\circ} \mathrm{C}}$ saturasyon çamurunda ölçülmüştür, ${ }^{* * *}$ Amonyum asetat ile ekstrakte edilebilir formudur, ${ }^{* * *}$ DTPA ile ekstrakte edilebilir formudur

\section{Yetiştirilen bitkiler}

Denemede tek yıllık yem bitkilerinden baklagil olan soyanın (Glycine max L.) Yemsoy çeşidi ve buğdaygil olan mısırın (Zea mays L.) Cadız çeşidi kullanılmıştır. Söz konusu bitkilere ait tohumlardan soya, Doğu Akdeniz Tarımsal Araştırma Enstitüsü Müdürlüğü, mısır ise Torunoğlu Tohumculuk firmasından alınmıștır.

\section{Denemenin kurulması ve yürütülmesi}

Araziden alınan toprak örnekleri hava kuru duruma geldikten sonra ahşap tokmakla dövülüp $4 \mathrm{~mm}$ 'lik elekten geçirilmiştir. Denemenin yürütülmesindeki bazı aşamaları gösteren resimler Şekil 1 olarak sunulmuştur. Elenmiş topraklar boyutları 250 × 250 × $150 \mathrm{~mm}$ (boy-en-derinlik) olan ve tabanındaki drenaj deliklerinin üzeri kaba filtre kağıdı ile örtülen metal toprak tavalarına yerleștirilmişler ve tavalara konulan toprakların ağırlıkları belirlenmiștir. Samanlı su tutucu Natural Aquatic $®$ tavalara kuru ağırlık esasına göre kontrol dahil 6 farklı dozda (\% 0, 0.1, 0.2, 0.4, 0.8 ve $1 \mathrm{w} / \mathrm{w}$ ) uygulanmış ve kuru iken homojen olarak karışması sağlanmıştır. Denetler ve karışımlar tekrar tavalara yerleştirilmiştir. Bu işlem yapılırken toprağın ıslandığında gerek yüksek kil içeriğinden gerekse uygulanacak su tutucu polimerin su aldığında şişerek hacmi artacağından toprak üst seviyesi tavanın yüzey akış toplama önlüğü yüksekliğinin biraz altında bırakılmış ve yüzeyi düzeltilmiştir (Şekil 1a). Daha sonra yukarıda özellikleri verilen 5 adet soya ve 10 adet mısır tohumu ekimi yapılan tavalar çeşme suyu ile tarla kapasitesine getirilmiştir. Bazı karşılaştırmaların yapılabilmesi için su tutucu polimer dozları uygulanan fakat tohum ekimi yapılmayan bir seri daha hazırlanmıştır. Deneme süresince tavalar $350 \mathrm{umol} \mathrm{m}{ }^{2} \mathrm{~s}^{-1} \mathrm{PPFD}$ ışık, 24/20 ${ }^{\circ} \mathrm{C}$ gündüz/gece sıcaklık, 16 saat aydınlık/8 saat karanlık ve \% 60/70 gündüz/gece nem (Sinsewat ve ark., 2004) şartlarında tutulmuştur 
(Şekil 1b). Kontrol saksılarında nem tarla kapasitesinin yaklaşık yarısına düștüğünde tavalar tekrar çeşme suyu ile tarla kapasitesine getirilmiştir. Bitki çıkışından sonra tavalarda seyreltme işlemi yapılmış ve her bir tavada soyadan 3, mısırdan ise 5 bitki bırakılmıştır (Şekil 1c). Çalıșma bölünmüș parseller deneme desenine göre 3 tekrarlamalı olarak kurulmuş, ana parsellerde bitkilere, alt parsellerde samanlı su tutucu Natural Aquatic ${ }^{\circledR}$ polimerin dozlarına yer verilmiştir. Bitkiler beş haftalık iken deneme sonlandırılmıştır. Toprak yüzeyinden kesilerek bitkiler uzaklaştırıldıktan sonra tavalar bir hafta süre ile tekrar aynı kontrollü koşullarda tutulmuş ve bu periyottan sonra sediment ve yüzeysel akış ölçümlerine geçilmiştir.

\section{Su ve toprak kaybı ölçümleri}

Toprak tavalarına \% 9 eğim verilerek 4 dakika süre ile yoğunluğu $360 \mathrm{~mm} \mathrm{~h}^{-1}$ olan yapay yağış uygulaması yapılmıştır (Şekil 1d). Deneme toprağı yüksek kil içeriğine sahip olduğundan ve superabsorbent polimerler çok fazla miktarda su tutabildiğinden, Natural Aquatic® polimerin yapay yağış altında toprak ve su kayıplarına nasıl etki edeceğini açıklamada daha tutarlı sonuçlar vereceği öngörüldüğünden yüksek intensiteli yağışla çalışılmıştır. Yağmurlama işleminde Eijkelkamp firması tarafından seri üretimi yapılan mini yağış simülatörü (Ürün Kodu: M1.09.06.E, type LUW, Eijkelkamp Agrisearch Equipment, 6987 ZG Giesbeck, Netherlands) kullanılmıştır. Aynı simülatör birçok araştırmacı tarafından benzer amaçlarla yüksek yağıș intensitesi ve değişik yağmurlama süreleri ile kullanılmıștır (Parlak, 2012, Martin ve ark., 2010, Nciizah ve Wakindiki 2014, Yakupoğlu, 2017).

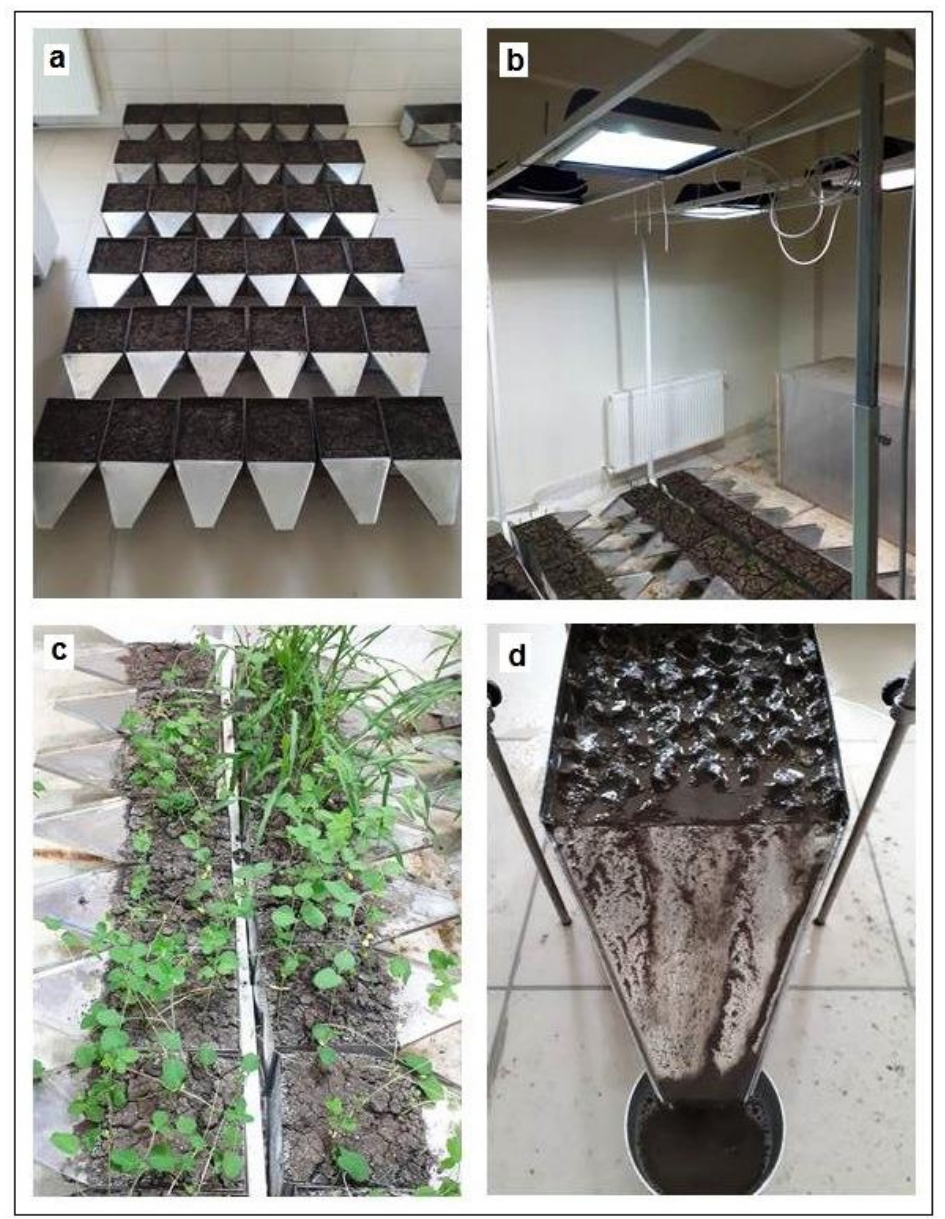

Şekil 1. Denemenin kurulması, yürütülmesi ve ölçümlere ait fotoğraflar (a: Su tutucu polimer uygulanmış toprak tavalarının bir bölümüne ait görünüm, b: Kontrollü koşullardaki toprak tavaları, c: Gelişen soya ve mısır bitkileri, d: Yapay yağış altında yüzeysel akış ve toprak kaybı ölçümü)

Bu drop-former tipindeki yapay yağmurlayıcı, 49 adet damla oluşturucu taşıyan bir yağmurlama haznesi ile bu haznedeki basıncı düzenleyen $2.3 \mathrm{~L}$ hacimli su yükü ünitesinden oluşmaktadır. Damlatıcıların uzunluğu $10 \pm 1 \mathrm{~mm}$, iç çapları ise $0.6 \pm 0.08 \mathrm{~mm}$ 'dir. Etkili yağmur alanı $0.0625 \mathrm{~m}^{2}$, damla uçuş uzunluğu $40 \mathrm{~cm}$ 'dir. Ürün katalogunda kalibrasyon için verilen $360 \mathrm{~mm} \mathrm{~h}^{-1}$ intensiteli yağış yağdırıldığında, bir damlanın kütlesi 0.106 g ve çapı $5.9 \mathrm{~mm}$ olmakta, yağan yağışın birim kinetik enerjisi ise $4 \mathrm{~J} \mathrm{~m}^{-2} \mathrm{~mm}^{-1}$ olmaktadır (Eijkelkamp, 2015). 
Simülatörün yağdırdığı yağışın yoğunluğu, kullanılan yağmurlama suyunun viskozitesinden ve zamanla kapillar yağmurlama başlıklarının çeşitli nedenlerle tıkanmasından etkilenmektedir (Yakupoğlu, 2017). Bu nedenle her çalışma gününün başlangıcında aletin kalibrasyonu yapılmıştır. Kalibrasyonda mükemmel akış

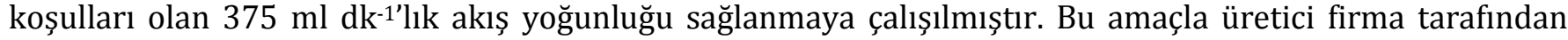
önerilen su yükü haznesindeki hava alma borusunun yüksekliği Eşitlik 1 kullanılarak hesaplanmış (Eijkelkamp, 2015) ve simülatörde hava borusu yüksekliği ayarlanmıştır.

$$
\mathrm{h}=100-0.65 \mathrm{xt}
$$

Burada:

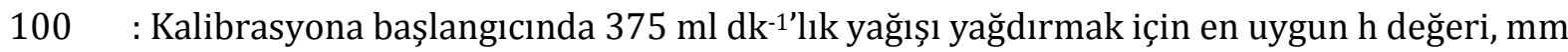

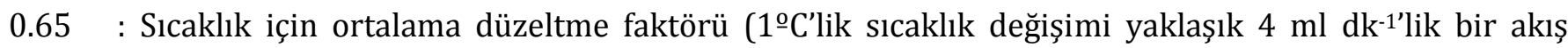
değişimine neden olmaktadır)

$\mathrm{T} \quad$ : yağmurlama suyunun sicaklı̆ğ, $\mathrm{o} \mathrm{C}$

Yağmurlamada saf su kullanılmıştır. Yağışın başlaması ile birlikte zaman tutulmaya başlanmış ve yüzey akışın başladığı süre kaydedilmiştir. Yağmurlama süresinin sonunda tavanın önlügüne yerleștirilen toplama kabı, sedimentin çökmesi amacıyla bir gece süre ile dinlenmeye bırakılmıştır. Dinlenme süresinden sonra yüzey akış suyu sifonlanarak hacmi ölçülmüş, geri kalan sediment ise $105^{\circ} \mathrm{C}^{\prime}$ sıcaklıkta sabit ağırlığa ulaşıncaya kadar etüvde kurutularak kütlesi ölçülmüştür. Uygulamaların ölçülen değişkenler üzerine etkinliklerinin değerlendirilmesinde ANOVA, etkin konuların birbiri ile karşılaştırılmasında ise Duncan testi kullanılmıştır. Bu istatistiksel değerlendirmelerin yapılmasında SPSS Version 20 paket programı kullanılmıştır (Efe ve ark., 2000).

\section{Bulgular ve Tartışma}

Denemeyi teşkil eden erozyon tavalarından $360 \mathrm{~mm} \mathrm{~h}^{-1}$ intensiteli ve 4 dakika süreli yapay yağış altında oluşan yüzeysel akış (YA) ve oluşan bu yüzeysel akışla taşınan toprak miktarı (YATT) bağımlı değişkenlerine ait tanımlayıcı istatistikler Çizelge 3'de verilmiştir. Söz konusu çizelgeye göre YA 0.37-7.17 mm arasında, YATT ise $20-405 \mathrm{~g} \mathrm{~m}^{-2}$ arasında değişmiştir.

Çizelge 3. Tanımlayıcı istatistikler

\begin{tabular}{llllll}
\hline Değişkenler & $\mathrm{N}$ & En düşük & En yüksek & Ortalama & Standart hata \\
\hline YA & 18 & 0.37 & 7.17 & 2.8861 & 2.12359 \\
YATT & 18 & 20 & 405 & 143.92 & 107.330 \\
\hline YA: Yüzzey aks & miktar $(\mathrm{mm})$ YATT: Yüzus
\end{tabular}

YA: Yüzey akış miktarı (mm), YATT: Yüzeysel akışla taşınan toprak miktarı $\left(\mathrm{g} \mathrm{m}^{-2}\right)$

Yapay yağış altında, her bir tavada yüzey akışın başlama zamanı bitkiler ve samanlı su tutucu dozlarına göre Şekil 2'de sunulmuştur. Adı geçen şekle göre, bitki yetiştirilmeyen tavalara uygulanan su tutucunun düşük dozları yüzeysel akışın başlamasını kontrole göre geciktirmiş, ancak yüksek su tutucu dozları yüzeysel akışın kontrolden daha erken başlamasına neden olmuştur. Mısır bitkisi yetiștirilen tavalarda, samanlı su tutucunun \%1 dozunun uygulandığı tava hariç yüzeysel akış kontrole göre daha geç başlamıştır. Soya yetiştirilen tavalarda ise uygulanan su tutucu polimer dozu arttıkça yüzey akışın başlaması daha da gecikmiştir. Şekil 2'ye göre yüzeysel akış en erken mısır bitkisi yetiştirilen \%1 su tutucu uygulanmış tavada yağıșın başlamasından 42 sn. sonra başlamıştır. Bitki yetiştiriciliği yapılmayan, su tutucunun \%0.8 ve \%1 dozlarının uygulandığı erozyon tavalarında da yüzeysel akış erken başlamıștır (sırasıyla 43. ve 44. saniyeler). Yüzeysel akışın en geç başladığı erozyon tavaları soya yetiştirilmiş olan ve yüksek doz su tutucu uygulanan tavalar olup yağış başladıktan 200 sn. sonra \%1 su tutucu uygulanan tavada yüzey akış başlamıştır.

Yapay yağış altında oluşan yüzey akış (YA) ve bu yüzeysel akışla taşınan toprak miktarı (YATT) veri kümesine uygulanan ANOVA sonuçları Çizelge 4'de verilmiştir. Çizelge 4'e göre ölçülen değişkenler üzerine bitkilerin bir etkisi olmamış ancak samanlı su tutucu uygulama dozunun YATT’ye etkisi $P<0.05$ düzeyinde önemli bulunmuştur. Tavalardan taşınan toprak miktarına etkileri bakımından dozların karşılaştırıldığı Duncan testi sonuçları Çizelge 5'de sunulmuştur. Bahsi geçen çizelgeye göre, en fazla YATT su tutucu uygulanmayan tavalardan oluşmuş (304.67a) bunu aralarında istatistiksel olarak fark bulunmayan en düşük ve en yüksek su tutucu dozları (\%1 ve \%0.1) uygulanan tavalar izlemiștir. En az YATT ise istatistiksel bakımdan birbirinin aynı olan ara dozların (\%0.8, \%0.4 ve \%0.2) uygulandığı tavalardan olușmuștur. 


\begin{tabular}{lllllll}
\hline \multicolumn{2}{l}{$\begin{array}{l}\text { Çizelge } \\
\text { 4. Ölçülen değişkenlere ait ANOVA sonuçları }\end{array}$} & & & & \\
\hline $\begin{array}{l}\text { Varyasyon } \\
\text { kaynağı }\end{array}$ & Bağımlı değişken & KT & SD & KO & F & Önemlilik \\
\hline Bitki & YA & 16.234 & 2 & 8.117 & 2.420 & 0.139 \\
& YATT & 5539.137 & 2 & 2769.568 & 0.394 & 0.690 \\
Doz & YA & 26.887 & 5 & 5.377 & 1.603 & 0.245 \\
& YATT & 119946.892 & 5 & 23989.378 & 3.410 & 0.047 \\
\hline
\end{tabular}

YA için $\mathrm{R}^{2}=0.562$, YATT için $\mathrm{R}^{2}=0.621$

KT: Kareler toplamı, SD: Serbestlik derecesi, KO: Kareler ortalaması, F: Hesaplanan F değeri

YA: Yüzeysel akış, YATT: Yüzeysel akışla taşınan toprak miktarı

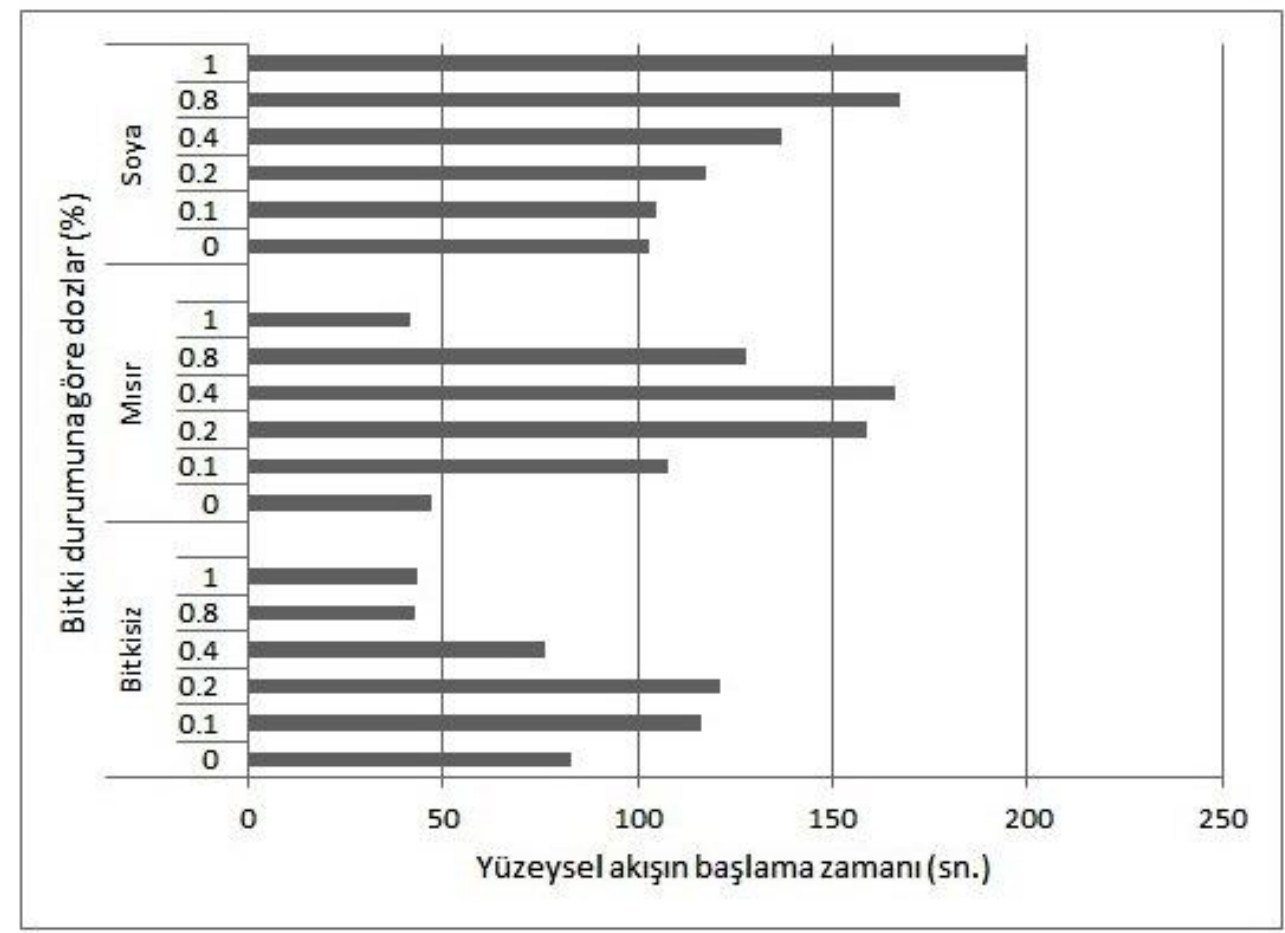

Şekil 2. Bitki durumu ve uygulamalara göre erozyon tavalarında yüzeysel akışın başlama zamanı

Çizelge 5. Tavalardan taşınan toprak miktarına etkileri bakımından dozların Duncan ile çoklu karşılaştırmasıı

\begin{tabular}{lc}
\hline Doz $(\%)$ & YATT $\left(\mathrm{g} \mathrm{m}^{-2}\right)$ \\
\hline 0.2 & $67.68 \mathrm{~b}$ \\
0.4 & $76.41 \mathrm{~b}$ \\
0.8 & $89.86 \mathrm{~b}$ \\
0.1 & $153.39 \mathrm{ab}$ \\
1 & $171.50 \mathrm{ab}$ \\
0 & $304.67 \mathrm{a}$ \\
\hline
\end{tabular}

$\alpha=0.05$, Hata terimi $=7034.892$

YATT: Yüzeysel akıșla taşınan toprak miktarı

Her ne kadar varyasyon kaynaklarının yalnızca birinin ölçülen değişkenlerden sadece YATT üzerine etkisi istatistiksel bakımdan anlamlı çıksa da erozyon tavalarından yapay yağış altında meydana gelen toprak ve su kayıplarını bitkiler ve samanlı su tutucu dozları üzerinden ayrı ayrı incelemekte büyük fayda vardır. Bitkiler ve uygulamalara göre erozyon tavalarından meydana gelen ortalama YA miktarları sütun grafikler halinde Şekil 3'de verilmiștir. Şekil 3'den de görüleceği üzere bitkisiz grubunda en fazla YA, samanlı su tutucunun en yüksek dozu olan \%1 uygulama tavasında $(7.17 \mathrm{~mm})$, en düşük YA ise $\% 0.2$ uygulama tavasında meydana gelmiştir. Bitki yetiştirilmemiş erozyon tavalarında YA miktarını kontrole göre azaltma bakımından samanlı su tutucunun düşük dozları etkili olmuş, en düşük miktarda YA \%0.2 su tutucu uygulanmış tavadan $(0.90$ $\mathrm{mm}$ ) meydana gelmiștir. Şekil 3'e göre mısır yetiștirilmiş olan tavalarda YA'yı kontrole göre azaltmada bütün dozlar etkili iken en etkili dozlar \%0.2 ve \%0.4 olmuştur (oluşan YA kalınlığı sırasıyla 0.95 ve $0.84 \mathrm{~mm}$ ). En yüksek ve en düşük dozların etkinlikleri diğer dozlardan daha düşük seviyede kalmıştır. Soya yetiștirilmiş olan erozyon tavaları üzerinden Şekil 3 incelendiğinde samanlı su tutucunun artan dozlarına karşılık YA'nın düzenli bir azalış gösterdiği görülmektedir. Bu tavalar içerisinde en yüksek YA $3.22 \mathrm{~mm}$ ile kontrol tavasından meydana gelirken, en düşük YA $0.37 \mathrm{~mm}$ ile \%1 doz uygulanmış tavada saptanmıștır. 


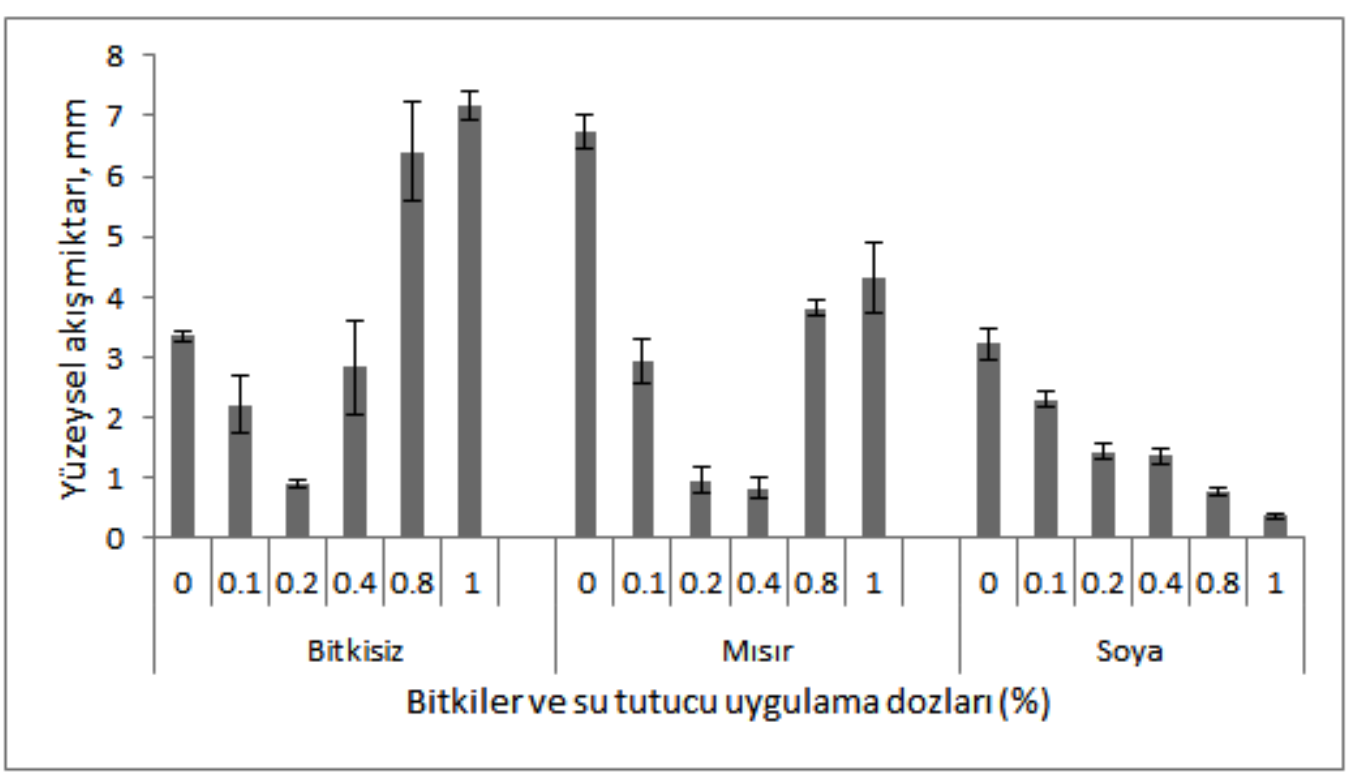

Şekil 3. Bitkiler ve uygulamalara göre erozyon tavalarından meydana gelen yüzeysel akışlar

Elde edilen bu sonuçlar, yüzey akışın yağışın başlamasından ne kadar sonra başladığı ile ilişkilidir çünkü yağış süresi her bir uygulama için eşit olduğundan yüzeysel akışın başlaması için geçen süre akışın kalınlığını etkilemektedir. Yüzey akışın başlama zamanı ile YA arasındaki ilişki grafiği Şekil 4'de verilmiștir. Söz konusu şekle göre akışın başlaması için geçen süre ile YA miktarı arasında üstel bir ilişki $\left(\mathrm{R}^{2}=0.85\right)$ vardır. Yani yüzey akışın başlaması için geçen süre uzadıkça YA dramatik olarak azalmaktadır. Akışın kalınlığının, akışın başlama süresi uzadıkça azaldığı, yapay yağış koşullarında yürütülen birçok çalışmada (Yakupoğlu ve Öztaş, 2016; Yakupoglu, 2017) tespit edilmiştir. Öte yandan YA miktarlarının birbirinden farklı olması, samanlı su tutucunun farklı dozlarda uygulanmış olmasına, bitki gruplarında YA seyrinin farklı olması da yetiştirilen bitkilerin kök sistemlerinin farklı olmasına atfedilebilir. Yağmurlama öncesi toprak nem içerikleri benzer olduğundan, ağırlık esasına göre farklı dozlarda uygulanan samanlı su tutucu erozyon tavalarında değişik miktarlarda yağıș suyunu bünyelerinde tutmuşlardır. Sadece polimer uygulanan ve polimer uygulamasıyla birlikte mısır yetiştirilen erozyon tavalarında samanlı su tutucunun özellikle $\% 0.2$ ve \%0.4 dozlarının yüzeysel akışı azaltmadaki başarısı; en düşük dozun yeterince su absorbe edememesine ve en yüksek dozun da aşırı su absorblayarak gereğinden fazla şişme sonucu toprak gözeneklerini tıkaması nedeniyle infiltrasyon oranını düşürmesine atfedilebilir. Bu anlamda, çok yüksek olmamakla birlikte, mısır, polimerin düşük ve yüksek dozlardaki olumsuz etkisini azaltmıştır. Soya yetiştirilen tavalarda ise artan samanlı su tutucu dozlarının seyrine uyumlu olarak YA azalmıștır. YA üzerinde bitkilerin etkisinin farklı olması, bitkilerin kök sistemlerindeki farklılı̆̆a atfedilebilir. Nitekim mısır saçak ve yüzlek soya ise kazık ve derin bir kök gelişimine sahiptir. Mısır kökleri üst toprakta yoğunlaşırken, soyanın kökleri profil boyunca daha dengeli dağılmış, üstelik derinlere inen kazık kökler toprağın infiltrasyon yeteneğini olumlu etkilemiştir. Nitekim baklagiller sahip oldukları kazık kökleri vasıtasıyla toprağın su alma hızını ve miktarını arttırmaktadır (Eser ve ark., 1998).

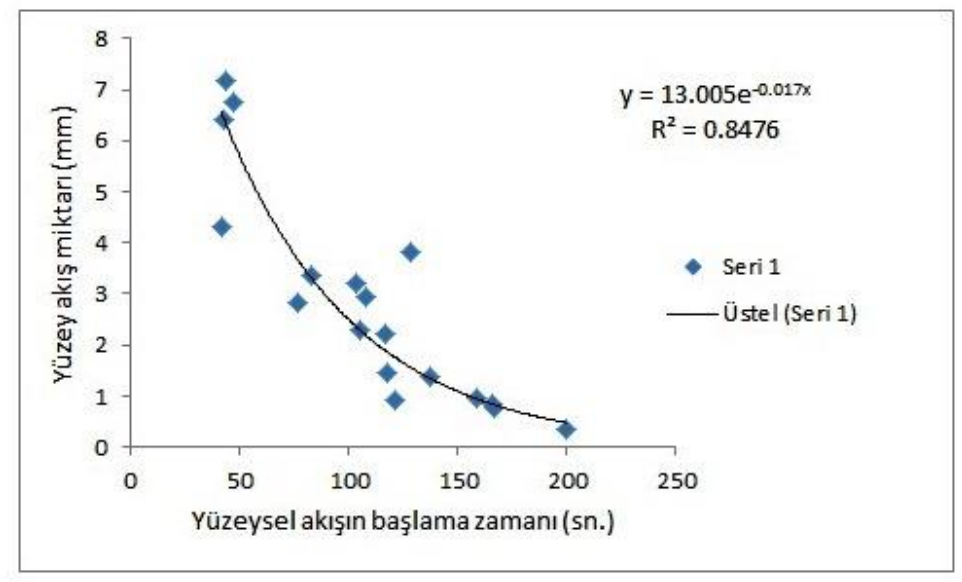

Şekil 4. Tavalardan meydana gelen yüzey akış ve yüzey akışın başlama zamanları arasındaki ilişki grafiği 
Her toprağın karakteristiğine göre farklı olmakla birlikte, bu tip polimerlerin genellikle \%0.1-\%0.5'lik dozları tavsiye edilmekte (Nciizah ve Wakindiki, 2014), bünyelerinde așırı miktarda su tuttuğuna dikkat çekilmektedir (Barbucci ve ark., 2000). Bu çalışmada, çok düşük ve çok yüksek dozlarda su tutucu uygulandığında, daha fazla yüzeysel akış meydana gelmiş olmasının, \%9 eğim verilmiş tavalarda, azalan infiltrasyon ya da yetersiz su tutulması neticesinde gerçekleștiği düşünülmektedir.

Bitkiler ve uygulamalara göre erozyon tavalarından meydana gelen ortalama YATT değerleri Șekil 5'de sütun grafikler halinde sunulmuştur. Bahsi geçen şekle göre, uygulanan samanlı su tutucunun YATT'ye etkisi YA üzerine olan etkisi ile benzerlik göstermiştir. Bitki yetiştirilmemiş ve mısır yetiştirilmiş tava grupları incelendiğinde, en düşük YATT'lerin orta doz samanlı su tutucu uygulamaları (\%0.2 ve \%0.4) yapılan tavalardan geçekleştiği görülmektedir. Soya yetiştirilmiş grup incelendiğinde ise bütün polimer uygulama dozlarının kontrole göre YATT'yi azaltmada başarılı olduğu, samanlı su tutucu dozu azaldıkça YATT’nin arttığı belirlenmiştir. Bitkisiz grubunda en yüksek YATT’ler samanlı su tutucu uygulanmayan tava ile en düşük ve en yüksek doz olan \%0.1 ve \%1 dozlarının uygulandığı tavalardan sırasıyla 194, 198 ve $214 \mathrm{~g} \mathrm{~m}^{-2}$ şeklinde gerçekleşmiştir. Mısır grubunda en yüksek YATT kontrol tavasından ( $405 \mathrm{~g} \mathrm{~m}^{-2}$ ) ve en yüksek doz olan \%1'in uygulandığı tavadan $\left(281 \mathrm{~g} \mathrm{~m}^{-2}\right)$ gerçekleşmiştir. Gerek bitki yetiştirilmemiş gerekse mısır yetiştirilmiş olan tavalarda YATT’yi azaltmada en etkili samanlı su tutucu dozu \%0.2 olmuştur (bitkisizde 75 $\mathrm{g} \mathrm{m}^{-2}$ ve mısırda $43 \mathrm{~g} \mathrm{~m}^{-2}$ ). Soya yetiştirilen tavalarda ise durum biraz farklıdır. Bu grupta en yüksek YATT kontrol tavasından oluşmuş (314 $\mathrm{g} \mathrm{m}^{-2}$ ), samanlı su tutucu dozu arttıkça yapay yağış altında yüzeysel akışla oluşan toprak kaybı azalmış ve en düşük YATT \%1 doz uygulamasının yapıldığı erozyon tavasından $(20 \mathrm{~g} \mathrm{~m}$ $\left.{ }^{2}\right)$ meydana gelmiştir.

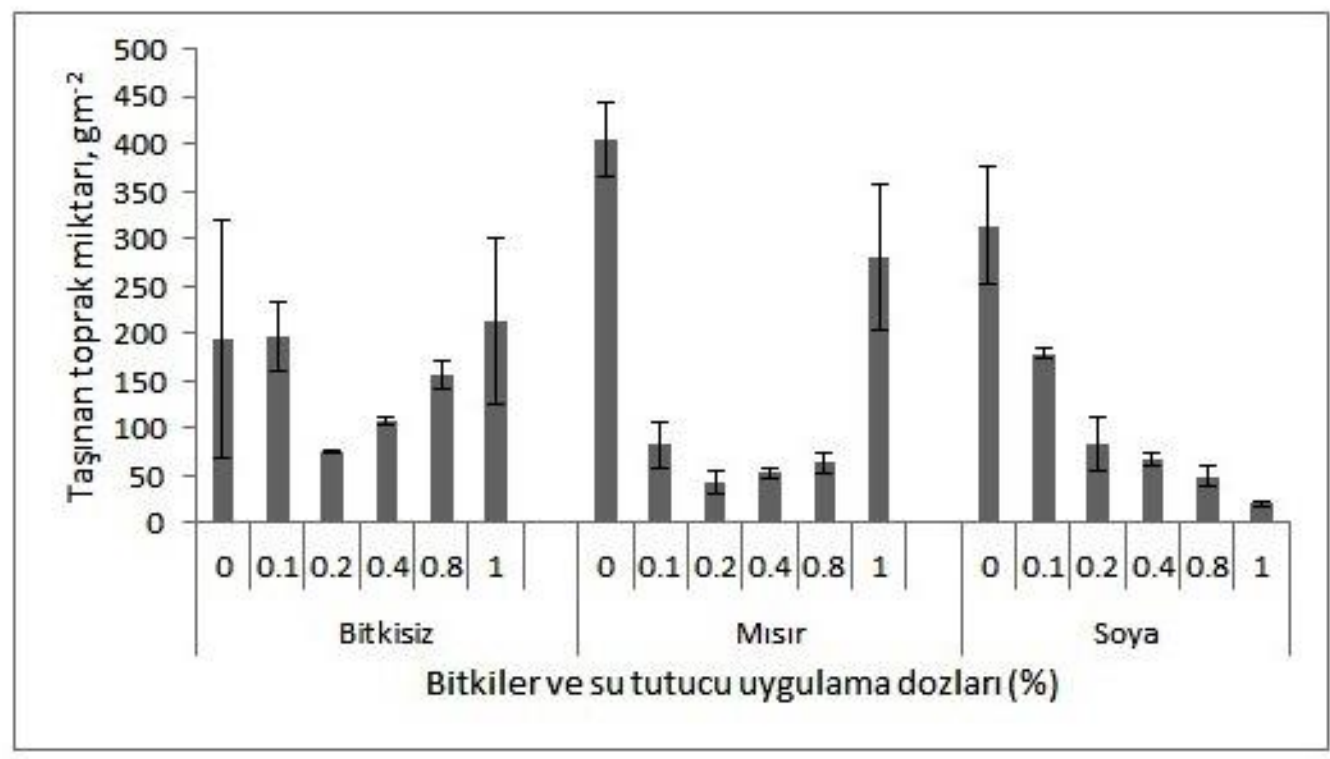

Şekil 5. Bitkiler ve uygulamalara göre erozyon tavalarından meydana toprak kayıpları

Eğimli koşullarda oluşacak toprak kayıpları elbette ki yağış özellikleri ve toprak özelliklerine sıkı sıkıya bağımlıdır (Kay ve Angers, 2000; Kinnell, 2005). Ancak bu çalışmada tek tip toprak kullanıldığından ve tek tip yapay yağış yağdırıldığından, dozların taşınan toprak miktarı üzerine etkilerini oluşan yüzeysel akış miktarları üzerinden tartışmak daha yerinde olacaktır. Erozyon tavalarından meydana gelen YATT’nin oluşan YA ile benzerlik göstermesi, genellikle YA miktarı ile YATT arasındaki ilişkiye atfedilebilir. Eğimli koşullarda yağış altında oluşan yüzeysel akışlar ve bu yüzeysel akışlarla taşınan toprak miktarı arasında çeşitli ilişkilerin tespit edildiğine dair birçok yayınlanmış eser bulunmaktadır (Poessen ve Ingelmo-Sanchez, 1992; Zheng ve Gao, 2001; Kılıç ve Yönter, 2005; Yakupoğlu, 2017). Bu çalışmada da YA ve YATT arasında bir üs ilişki tespit edişmiş $\left(\mathrm{R}^{2}=0.69\right)$, ilişkiye ait dağılım grafiği Şekil 6'da sunulmuştur. Adı geçen şekle göre YA kalınlığı arttıkça erozyon tavalarından oluşan YATT miktarı da artmış, bir noktadan sonra YA miktarındaki artışa karşılık YATT'nin artışı azalarak devam etmiştir. Başlangıçtaki düzenli artış, soyanın, samanlı su tutucunun yüksek dozunun neden olduğu yukarıda anlatılan olumsuz etkilerini baskılamış olmasından kaynaklanabilir. Yüzeysel akış miktarının artışı ile birlikte bir noktadan sonra eğrinin giderek eğilmesi ise bitkisiz ve mısır tava gruplarında, en düşük ve en yüksek uygulama dozlarının en kalın yüzeysel akışlara neden olmuş olmasına atfedilebilir. 


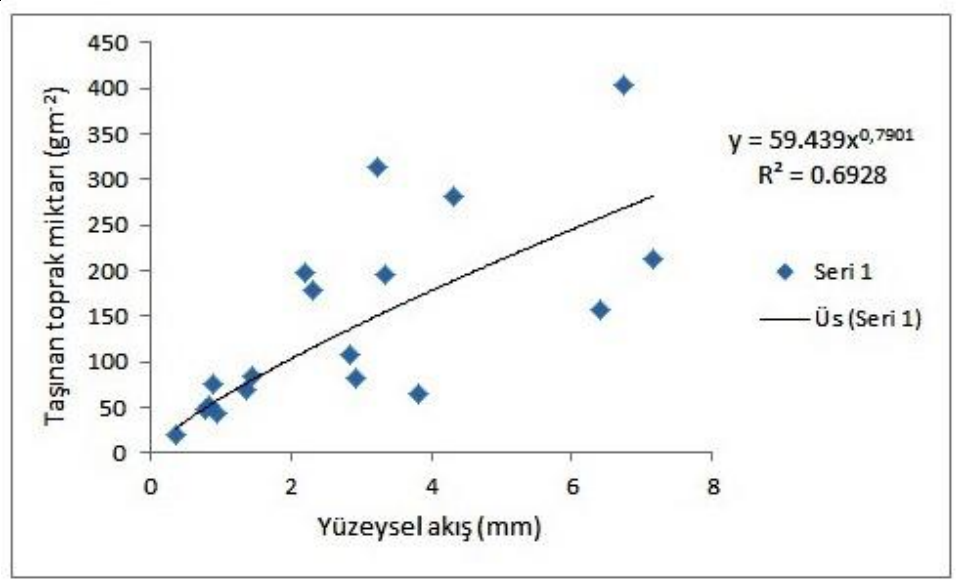

Şekil 6. Tavalardan meydana gelen yüzeysel akış ve bu akışla taşınan toprak miktarı arasındaki ilişki grafiği Toprağa agregat stabilizeri olarak uygulanan polimerlerin dozları yetersiz geldiğinde birçok toprak dinamiği ve dış faktörlere bağlı olarak bazen yüzeysel akışları artabilmektedir (Yolcu, 2001; Yakupoglu ve ark., 2012). Bu çalışmada kullanılan superabsorbent polimer her ne kadar agregat stabilize edici olmayıp bir su tutucu olsa da \%0.1 uygulama dozu yetersiz geldiği için bitkisiz grubunda yeterli suyu tutulamadığından kontrole göre bir miktar fazlaca yüzey akış oluşmuş olabilir. Samanlı su tutucu dozlarının erozyon tavalarından taşınan toprak miktarına etki etmesi, oluşan yüzeysel akışın miktarına bağlı olduğu gibi topraktaki gözenek büyüklük dağılımları ile de ilintilidir (Yu ve ark., 2011). Denemede kullanılan toprak kil bünyelidir (Çizelge 1). Genel olarak su tutma kapasitesi yüksek olan bu topraklarda samanlı su tutucunun yüksek dozları gözeneklerin çok çabuk tıkanmasına ve böylelikle hidrolik iletkenliğin düşmesine neden olmuş olabilir. Toprak özellikleri, su tutucunun topraktaki etkinliğini değiştirebilmektedir (Huttermann ve ark., 2009). Bitki köklerinin agregasyon üzerine çok çeşitli etkileri bilinmektedir (Degens, 1997; Angers and Caron, 1998). Bitki yetiştirilmiş olan erozyon tavalarında düşük dozun herhangi bir sorun çıkarmamış olması, mısır ve soya köklerinin agregasyona katkı sağlayarak tavalardaki toprakların gözenek sürekliliğini sağlamış olabileceğine atfedilebilir.

\section{Sonuç}

$\mathrm{Bu}$ çalışmadan elde edilen sonuçlara göre, toprak ve su kayıplarına etkisi bakımından, yarı-kurak iklim bölgesi topraklarında Natural Aquatic ${ }^{\circledR}$ isimli samanlı su tutucu polimerin $\% 0.2$ ve $\% 0.4$ dozları, eğimin \%9'u aşmadığı, mısır yetiştiriciliğinin yaplacağı kil bünyeli topraklar için uygundur. Eğimin < \%9 olduğu soya yetiştirilecek alanlarda ise daha yüksek dozlar kullanılabilir. Günümüz koşullarında henüz ekonomik bir uygulama olmamakla birlikte, yarı-kurak iklim bölgelerinde nadas alanlarına bu su tutucuların uygulanması tercih edilirse, \%9'a kadar eğimli alanlar için bu polimerin $\% 0.8$ ve üzeri uygulama dozu aşırı toprak ve su kayıplarına neden olacağından dolayı sakıncalıdır. Su tutucu polimerlerin topraktaki davranışları ve değişik koşullarda vereceği davranışlarla ilgili henüz büyük bilinmezlikler bulunmaktadır. Konunun daha çok aydınlığa kavuşabilmesi için Natural Aquatic® superabsorbentinin ara dozları denenmeli, değişik toprak tiplerine göre içeriğindeki saman oranı kalibre edilmeli, farklı özelliklerdeki yapay yağışlar altında ve değişik eğim gruplarında denemeler yapılmalıdır. Bir sonraki aşamada denemeler parsel boyutuna taşınarak doğal yağışlar altında, farklı eğimli arazilerde, değişik bitkilerin yetiştirileceği çalışmalar yürütülmelidir.

\section{Teşekkür}

Bu çalışma, Türkiye Bilimsel ve Teknolojik Araştırma Kurumu (TÜBİTAK) tarafından 2209-A Üniversite Öğrencileri Araştırma Projeleri Destekleme Programı (Başvuru numarası: 1919B011700972) altında desteklenen bir projenin materyali kullanılarak gerçekleștirilmiştir. Çalışmada kullanılan samanlı su tutucu olan Natural Aquatic ${ }^{\circledR}$ polimeri, Doç. Dr. Orhan Hazer aracılığı ile Bozok Üniversitesi Teknoparkı Hazerfen Kimya Şirketi'nden temin edilmiştir. Adı geçen kurum, kuruluş ve kişilere teşekkür ederiz.

\section{Kaynaklar}

Angers DA, Caron J, 1998. Plant-induced changes in soil structure: processes and feedbacks. Biogeochemistry, 45: 55-72. Anonim 2018a. Natural Aquatic ${ }^{\circledR}$ internet sayfası. Available from URL: http://www.naturalaquatic.com.tr/tr

Anonim 2018b. Türk Akreditasyon Kurumu tarafından yapılan Natural Aquatic $®$ analiz sonuçları Available from URL: http://www.naturalaquatic.com.tr/tr/sayfa/9/analiz-raporu.aspx 
Baker SW, 1990. The use of amendment materials to improve grass establishment on a polypropylene, needle punched reinforcement. Journal Sports Turf Research Institute, 66: 76-88.

Barbucci R, Magnani A, Consumi, M, 2000. Swelling behavior of carboxymethylcellulose hydrogels in relation to crosslinking, $\mathrm{pH}$ and charge density. Macromolecules, 33: 7475-7480.

Bhardwaj A, Shainberg I, Goldstein D, Warrington DN, Levy GJ, 2007. Water retention and hydraulic conductivity of corss-linked polyacrylamides in sandy soils. Soil Science Society of America Journal 71: 406-4012.

Busscher WJ, Bjorneberg DL, Sojka RE, 2009. Field application of PAM as an amendment in deep-tilled US southeastern Coastal Plain soils. Soil \& Tillage Research 104(2): 215-220.

Degens BP, 1997. Macro-aggregation of soils by biological bonding and binding mechanisms and the factors affecting these: a review. Australian Journal of Soil Research 35: 431-459.

Efe E, Bek Y, Şahin M, 2000. SPSS'de Çözümleri ile İstatistik Yöntemler II. Yayın No: 73, KSÜ Yayınları, Kahramanmaraş.

Eijkelkamp, 2015. Manual. Available from URL: http://Pkd.Eijkelkamp.Com/Portals/2/Eijkelkamp/Files/Manuals/M10906e\%20rainfall\%20simulator.Pdf

Ekebafe LO, Ogbeifun DE, Okieimen FE, 2011. Polymer Applications in Agriculture. Biokemistri 23(2): 81-89.

Eser D, Adak M.S, Biesantsz A, 1998. Orta Anadolu koşullarında farklı toprak işleme, mercimek buğday ve nadas-buğday ekim nöbeti sistemlerinde mercimek ve buğdayda kök uzunluğu yoğunluğu ile toprakta infiltrasyon ölçümleri. Turkish Journal of Agriculture and Forestry 22: 483-489.

Esposito F, Del Nobile A, Mensitieri G, Nicholais L, 1996. Water sorption in cellulose-based hydrogels. Journal of Applied Polymer Science 60: 2403-2407.

Fan T, Stewart BA, Payne WA, Yong W, Luo J, Gao Y, 2005. Long-term fertilizer and water availability effects on cereal yield and soil chemical properties in northwest China. Soil Science Society of America Journal 69: 842-855.

Han YG, Yang PL, Xu L, 2005. Experimental studies on increase of yield and soil moisture of fruit tree by using superabsorbent polymers. Scientia Agricola 38: 2486-2491.

Han YG., Yang PL, Luo YP, Ren SM, Zhang LX, Xu L, 2010. Porosity change model for watered superabsorbent polymertreated soil. Environmental Earth Sciences 61: 1197-1205.

Huttermann A, Orikiriza JB, Agaba H, 2009. Application of superabsorbent polymers for improving the ecological chemistry of degraded or polluted lands. CLEAN - Soil, Air, Water , 37: 517-526.

Huttermann A, Zommorodi, M, Reise K, 1999. Addition of hydrogels to soil for prolonging the survival of Pinus halepensis seedlings subjected to drought. Soil \& Tillage Research 50: 295-304.

Ingram DL, Yeager TH, 1987. Effects of irrigation frequency and a water absorbing polymer amendment on Ligustrum growth and moisture retention by a container medium. Journal of Environmental Horticulture 5: 19-21.

Johnson MS, Piper CC, 1997. Cros-linked, water-storing polymers as aids to drought tolerance of tomatoes in growing media. Journal of Agronomy and Crop Science, 178: 23-27.

Karimi A, Noshadi M, Ahmadzadeh M, 2009. Effects of super absorbent polymer (Igeta) on crop, soil water and irrigation interval. Journal of Science and Technology of Agriculture and Natural Resources. 12:415-420.

Kay BD, Angers DA, 2000. "Soil Structure" in Handbook of Soil Science. Editör: Sumner, M.E. Crc Press, Boca Raton, FL. pp. 229-276.

Kazanskii KS, Dubrovskii SA, 1992. Chemistry and physics of agricultural hydrogels. Advances in Polymer Science 104: 97-133.

Kılıç M, Yönter G, 2005. Yağışla meydana gelen toprak kaybının yüzey akış miktarı ve yağış süresine bağlı değişiminin modellenmesi. Ege Üniversitesi Ziraat Fakültesi Dergisi 42(1):97-106.

Kinnell PIA, 2005. Raindrop-İmpact-induced erosion processes and prediction: a review. Hyrological Processes, 19: $2815-2844$

Lobo D, Torres D, Gabriels D, Rodriguez N, Rivero D, 2006. Effect of organic waste compost and a water absorbent polymeric soil conditioner (hydrogel) on the water use efficiency in a Caspium annum (green paper) cultivation. Agroenviron2006 Conference, 453-459, September 4-7, Ghent, Belgium.

Martin C, Pohl M, Alewell C, Körner C, Rixen C, 2010. Interrill erosion at disturbed alpine sites: Effects of plant functional diversity and vegetation cover. Basic and Applied Ecology, 11: 619-626.

MGM, 2018. T.C. Tarım ve Orman Bakanlığı Meteororloji Genel Müdürlüğü resmi internet sitesi. Available from URL: https://www.mgm.gov.tr/veridegerlendirme/il-ve-ilceler-istatistik.aspx?m=YOZGAT

Nciizah AD, Wakindiki IIC, 2014. Rainfall pattern effects on crusting, infiltration and erodibility in some African soils with various texture and mineralogy. Water SA, 40: 57-63.

Nnadi F, Brave C, 2011. Environmentally friendly superabsorbent polymers for water conservation in agricultural lands. Journal of Soil Science and Environmental Management, 2(7): 206-211.

Parlak M, 2012. Determination of soil erosion over different land uses by mini rainfall Simulator. Journal of Food, Agriculture \& Environment, 10: 3\&4, 929-933.

Pill WG, Jacono CC, 1984. Effects of hydrogel incorporation in peat-lite on tomato growth and water relations. Communications in Soil Science and Plant Analysis. 15: 799-810.

Poessen J, Ingelmo-Sanchez F, 1992. Runoff and sediment yield from topsoils with different porosity as affected by rock fragments cover and positions. Catena, 19(5): 451-474. 
Raju KM, Raju MP, Mohan YM, 2003. Synthesis of superabsorbent copolymers as water manageable materials. Polymer International 52: 768-772.

Sinsewat V, Leipner J, Stamp P, Fracheboud Y, 2004. Effect of heat stress on the photosynthetic apparatus in maize (Zea mays L.) grown at control or high temperature. Environmental and Experimental Botany, 52: 123-129.

Viero PWM, Chiswell KEA., Theron JM, 2002. The effect of a soil amended hydrogel on the establishment of Eucalyptus grandis clone on a sandy clay loam soil in Zululand during winter. Southern African Forestry Journal 193: 65-75.

Yakupoğlu T, 2017. Düzenleyici Olarak Kullanılan Bazı Polimerlerin Toprak ve Su Kayıpları Üzerine Etkilerinin Agregat Büyüklüğüne Bağlı Olarak Yapay Ardıl Yağışlar Altında Araştırılması. Proje Sonuç Raporu. TÜBİTAK, Proje No: 1130555.

Yakupoglu T, 2017. Effect of some polymeric materials on runoff and sediment quantity generated from Typic Xerochrept depending on initial aggregate size under sequential simulated rainfall. 1st World Conference on Soil and Water Conservation under Global Change (CONSOWA2017), Abstract Book: 106, .June 12-16, Lleida, Spain.

Yakupoğlu T, 2018. Bozok yöresinde araştırma amaçlı kullanılan tarım arazilerinin bazı toprak özellikleri ve bölgesel kalkınmaya katkı sağlayacak araştırmalar açısından çeşitli öneriler. III. Uluslararası Bozok Sempozyumu. 3-5 Mayıs, 2018, Yozgat, Türkiye.

Yakupoglu T, Oztas T, 2016. Effect of polyacrylamide and polyvinyl alcohol on runoff and sediment from an Entisol under simulated rainfall. Eurosoil-2016, Number: 101. October 16-21, İstanbul.

Yakupoglu, T., Özdemir, N., Dengiz, O., 2012. The effect of PAM and PVA applications on runoff and soil losses under simulated rainfall. International Scientific-Practical Conference on Rational Use of Soil Resources and the Environment. 526-530, November 15-16, Almaty, Kazakhstan.

Yolcu G, 2001. Bazı Polimerlerin Laboratuar Koşullarında Toprak Özellikleri ile Birlikte Yüzey Akış ve Toprak Kaybı Üzerine Etkileri. Doktora Tezi, Ege Üniversitesi Fen Bilimleri Enstitüsü, İzmir.

Yu J, Shainberg I, Yan YI, Levy GJ, Mamedov AI, 2011. Superabsorbents and semiarid soil properties affecting water absorption. Soil \& Water \& Conservation, 75(6): 2305-2313.

Yu J, Shi JG, Dang PF, Mamedov AI, Shainberg I, Levy GJ, 2012. Soil and polymer properties affecting water retention by superabsorbent polymers under drying conditions. Soil Science Society of America Journal 76(5): 1758-1767.

Zheng FL, Gao XT, 2001. Effects of up-slope runoff on erosion processes at down-slope shallow gully erosion areas. Sustaining the Global Farm (eds. Stott DE, Mohtar RH, Steinhardt GC) pp. 737-741. 